\title{
Dosing Schedule of Second Generation Sulfonylureas in the Treatment of Non-Insulin Dependent Diabetes Should be Revised (A Commentary)
}

\author{
Iwan Darmansjah
}

The second generation sulfonylureas, namely glibenclamide, glipizide and gliclazide which are available in Indonesia are much more potent than tolutamide and chlorpropamide (first generation) in releasing insulin from the beta-cells of the pancreas. Glibenclamide and glipizide have an effective plasma concentration of about $1 / 1000$ of those of tolbutamide and chlorpropamide. ${ }^{1}$

Dosing schedules of potent drugs such as second generation sulfonylureas must be carefully selected in order to be efficacious without causing dangerous hypoglycemic episodes. The package insert of the respective pharmaceutical products, in general, do not contain enough prescribing information. Although there is an uncertain correlation between the individual dose, the plasma concentration, and the glucose-lowering effect in non-insulin-dependent diabetes mellitus (NIDDM), most manufacturers will recommend $1 / 2$ to 3-4 tablets a day, to be increased with small increments when needed. However, not enough is mentioned about the correct time and frequency of ingestion and the maximal dose that should be given as a single administration. The Daonil (glibenclamide, Hoechst) package insert for instance states: "Unless otherwise prescribed, daily doses of up to 2 Daonil tablets are taken with or immediately after breakfast. If the daily dose exceeds 2 Daonil tablets, the remaining portion is taken after the evening meal". This may be assumed when patients have a big breakfast and small lunches and close the day with a good dinner. Some people may have no breakfast but eat a big carbohydrate-rich lunch and dinner. If this is the case, then the first sulfonylurea dose should preferably be given $0.5-1$ hour before lunch or the main meal, and it suffices to continue with another dose in the evening, also 0.5-1 hour before dinner. Administering the drug before meals has been shown to enhance efficacy for reasons stated below. 1,2

Maximal recommended daily doses of sulfonylureas vary considerably; for glipizide it is $40 \mathrm{mg}$ ( 8 tablets) in the United States and $15-20 \mathrm{mg}$ in Europe, while for glibenclamide it is $20 \mathrm{mg}$ ( 1 tablet contains either 2.5 or $5 \mathrm{mg}$ of the usual formulation) in the United States and $14 \mathrm{mg}$ of a more potent micronized formulation in Europe. Recently it has been shown that increasing the glipizide dose to more than $10 \mathrm{mg}$ once daily produces little or no benefit ${ }^{3}$ and may even reduce beta-cell function. Another earlier study ${ }^{4}$ found similar potency of glipizide compared to glibenclamide at $15 \mathrm{mg}$ per day, increasing this dose was also of little benefit.

Single dosing of sulfonylurea in the morning, using doses that would presumably be effective for 24 hours are perhaps not adequate, because serum drug concentration will begin to rise around 1-2 hours, reaching a maximum at about 4 hours ${ }^{5}$ after drug administration. Hereafter serum drug concentration decreases, often not enough to cover the main meal during the evening and perhaps late lunch if the drug is administered at breakfast only. To achieve prolongation of the sulfonylurea serum concentration and therapeutic goals, quite often, 2 tablets are given in the morning with disastrous hypoglycemic effect. I have seen numerous cases whereby type II diabetic patients are between life and death in the morning between 10 and 12 A.M. because of severe hypoglycemic bouts. Some patients may even regard such an episode as the beneficial therapeutic outcome of the drug. Great hunger accompanies this phenomenon and instinctively patients resort to eating and drinking sweet beverage which will not cease until the shaking is over. By this time blood glucose shoots up and when the patient goes to the laboratory later in the afternoon for his routine blood checks, postprandial glucose will be very high. The inadvertant physician, pressed by time so that no dialoque is held, will conclude that the dose of his sulfonylurea medication was insufficient. Moreover, some patients do not communicate to the doctor, because he or she may regard this as a natural outcome of the treatment. He or she may then be prescribed an even higher dose of the drug. 
Single morning dosing of potent drugs that are supposed to act for 24 hours with the aim of improving compliance are sometimes dangerous. They are assumed to work for 24 hours and so the dose is increased to higher than necessary. Glibenclamide, the most popular of the second generation sulfonylureas for instance, has a plasma half life of 2 hours or more, and even if the drug should work for most of the day and night, it does not do so evenly. With sulfonylureas this practise may lead to hypoglycemic episodes with dangerous outcome. I recommend that more doseresponse studies are conducted to determine the safe and efficient administration of oral antidiabetic drugs. A quarter to maximally 1 tablet, given 1 hour before each meal, should be more suitable than giving the total daily dose in the morning. Each dose should also be adjusted to the expected amount of food to be ingested. It is important to administer the drug $0.5-1$ hour before each meal in order that the rise of drug concentration coincides with the absorption of the food taken, hereby minimizing hypoglycemic episodes and its resultant tendency of compensatory overeating. When the expected time of meals cannot be well determined due to certain circumstances like when going to a reception, then the administration of the drug should be timed at a convenient moment well before food is served.

Blood glucose measurements should be done with the drug taken as usually and the patient should be instructed to do so. Many patients assume erroneously that when they are ordered for glucose checks by their physicians, oral antidiabetic drugs should be withheld that day. This will result in artificially high postpran- dial glucose values and consequently a larger dose than necessary may be prescribed by the attending physician.

In order that more dangerous encounters of this sort are prevented, physicians should be duly warned againts the above phenomenon and the drug industry should conduct more dosing studies and revise their package inserts accordingly. Results of artificially controlled clinical trials with rigid protocols should be critically assessed because it may not apply in real life situations where eating habits, especially of diabetic patients, are as diverse as food itself.

\section{REFERENCES}

1. Melander A, Bitzen P-O, Faber O, Groop L. Sulphonylurea antidiabetic drugs, An update of their clinical pharmacology and rational therapeutic use. Drugs 1989;37:58-72.

2. Wahlin- Boll E, Melander A, Sartor G, Schersten B. Influence of food intake on the absorption and effect of glipizide in diabetics and in healthy subjects. Eur J Clin Pharmacol 1980;18:279-83.

3. Stenman S, Melander A, Groop P-H, Groop LC. What is the benefit of increasing the sulfonylurea dose? Ann Int Med 1993;118:169-72.

4. Groop L, Groop P-H, Stenman S, et al. Comparison of pharmacokinetics, metabolic effects and mechanisms of action of glyburide and glypizide during long term treatment. Diabetes Care 1987;10:671-8.

5. El-Sayed YM, Suleiman MS, Hasan MM, et al. Comparison of the pharmacokinetics and pharmacodynamics of two commercial products containing glibenclamide. Int J Clin Pharmacol Ther Toxicol 1989;27:551-7. 